\title{
Changes and challenges in markets for animal source foods: a qualitative study among market vendors in Addis Ababa, Ethiopia
}

\author{
Lilia Bliznashka ${ }^{1}$ (D) - Simone Passarelli ${ }^{2}$ (D) Chelsey R. Canavan ${ }^{1}$ (D) - Amare Worku Tadesse ${ }^{3,4}$ (D) \\ Yemane Berhane $^{3}$ (D) Wafaie W. Fawzi ${ }^{1,2,5}$ (D)
}

Received: 26 March 2020 / Revised: 19 August 2020 / Accepted: 4 September 2020

(C) International Society for Plant Pathology and Springer Nature B.V. 2020

\begin{abstract}
Malnutrition is common in Addis Ababa, Ethiopia, in part due to suboptimal diets limited in essential nutrients. Despite previous dietary diversification efforts, animal source food (ASF) consumption remains low, potentially due to supply-side factors affecting ASF market vendors. This study sought to identify supply-side policies and interventions to support urban ASF market vendors and to alleviate the challenges they face. We conducted a qualitative study among 40 urban food market vendors (interviewed in February 2018) to investigate their perceptions of changes in ASF markets over time, the reasons behind these changes, and the challenges faced. Data were analysed using inductive thematic analysis. Findings showed that market vendors agreed that all ASF prices have increased in the past two years, driven by supply shortages, high input costs, consumer demand for ASFs and socio-economic status, among other less prominent causes. Vendors perceived their main challenges to be food supply, religious fasting, consumer demand, price increases and fluctuations, transportation, market infrastructure, and government policies. We identified several potential supply-side interventions and policies that can help optimize ASF markets and eliminate market inefficiencies, including: improving storage facilities to reduce dependability on seasonality; improving road infrastructure to reduce transportation costs and difficulties; stabilizing input costs; and improving the physical market infrastructure to ensure opportunities for business growth. These market-based policies and interventions can help support and stabilize ASF markets by alleviating the barriers faced by urban vendors.
\end{abstract}

Keywords Urban markets $\cdot$ Supply-side interventions $\cdot$ Value chain $\cdot$ Food prices

Lilia Bliznashka

lilia.bliznashka@gmail.com

1 Department of Global Health and Population, Harvard T.H. Chan School of Public Health, 665 Huntington Avenue, Building 1, 11th Floor, Boston, MA 02115, USA

2 Department of Nutrition, Harvard T.H. Chan School of Public Health, 665 Huntington Avenue, Boston, MA 02115, USA

3 Addis Continental Institute of Public Health, ACIPH Building, Yeka Sub-city, Ayat Zone 8, YK_13_4064, House number B227_23, P.O. Box 26751, /1000 Addis Ābaba, Ethiopia

4 Faculty of Epidemiology and Population Health, London School of Hygiene \& Tropical Medicine, Keppel Street, London WC1E 7HT, UK

5 Department of Epidemiology, Harvard T.H. Chan School of Public Health, 677 Huntington Ave, Boston, MA 02115, USA

\section{Introduction}

Ethiopia has the fifth largest economy and the second largest population in sub-Saharan Africa (SSA) (The World Bank 2019). Addis Ababa, the capital and largest city in Ethiopia, is home to 4.4 million people or approximately $4 \%$ of the population (Central Intelligence Agency 2019). Despite substantial improvements over the past few decades, undernutrition is still common in Addis Ababa, albeit less so compared to other urban or rural areas. In 2016, $15 \%$ of children were stunted and $50 \%$ were anaemic; $13 \%$ of women and $18 \%$ of men were underweight; and $16 \%$ of women and $5 \%$ of men were anaemic. Overnutrition is also rising among Addis Ababa residents: $30 \%$ of women and $20 \%$ of men are overweight or obese (Central Statistical Agency (CSA) [Ethiopia] and ICF 2016). Malnutrition has remained the top driver of death and disability in Ethiopia since 1990, accounting for 
$35 \%$ of disability-adjusted life years (DALYs) in 2017 (Institute for Health Metrics and Evaluation (IHME) 2019).

The high prevalence of malnutrition can be at least partially attributed to suboptimal diets, among other factors (Gebru et al. 2018). Ethiopian diets are primarily cereal-based with carbohydrates contributing $60 \%$ of energy, fat $30 \%$, and protein only $10 \%$. Inadequate intake of protein, zinc and vitamin $\mathrm{A}$ are common among men, women and children (Ethiopian Public Health Institute 2013). Animal source foods (ASF) are not widely consumed by adults in Addis Ababa: flesh foods contribute only $3 \%$ to the overall food quantity consumed among women and $5.5 \%$ among men, while dairy products and eggs represent even less. However, ASFs play an important role in children's diets, with dairy products accounting for $40 \%$ of overall food quantity (in grams) consumed by children 6-35 months of age (Ethiopian Public Health Institute 2013).

Although previous studies in Ethiopia show that ASF consumption is twice as high in urban compared to rural areas (Abegaz et al. 2018), overall ASF consumption remains low except for dairy consumption among children (Ethiopian Public Health Institute 2013). High prices are one of the main determinants of ASF demand (Abegaz et al. 2018). Although meat products contribute only $2 \%$ of total household calories, they account for $18 \%$ of food budget (Wolle et al. 2020). Onethird of Addis Ababa residents indicate they would first increase meat consumption if their budget increased (Melesse et al. 2019). However, little is known about the state of urban ASF markets in Ethiopia, and Addis Ababa in particular, and how they have changed over time. Previous work has focused on ASF production and value chains as major contributors to economic output (Alemayehu 2011; Benfica and Thurlow 2017; GebreMariam et al. 2010, 2013; Yilma et al. 2011), and has largely ignored market vendors as the link between food supply chains and consumers.

Urban markets in Ethiopia have become increasingly important due to high urban population growth (4.9\% over the past five years) (The World Bank 2019), food price shocks (Hill and Porter 2017), concerning use of coping strategies (e.g., reducing the number and size of meals) (WFP-Ethiopia 2009), and high food insecurity (Birhane et al. 2014). In Addis Ababa, as much as $75 \%$ of households are food insecure and $23 \%$ in a state of hunger. Food insecure households have lower dietary diversity, consume a lower quality diet, and shift to poor quality, less expensive foods to cope with high food prices (Birhane et al. 2014). Price shocks in staple foods generally increase food insecurity among urban dwellers, particularly those with low wealth (Matz et al. 2015). In addition, recent projections show that the size of urban ASF markets will quadruple in the next ten years (Abegaz et al. 2018). Between 2000 and 2030, beef and milk consumption growth rates in Addis Ababa are expected to increase by more than $300 \%$, while poultry and egg consumption growth rates are expected to increase by more than $600 \%$ (Robinson and Pozzi
2011). Consequently, a deeper understanding of ASF markets is necessary to ensure they can adequately help meet the nutrient needs of the population. Previously, dietary diversification efforts in Ethiopia have been limited by supply-side factors (e.g., accessibility and availability) (Ethiopian Public Health Institute 2013). Urgent evidence is needed on whether urban ASF markets can support demand-side policies, recommendations and interventions aimed at improving urban diets, or whether supply-side actions are necessary to help remove challenges and alleviate market failures and constraints.

In light of certain ASFs' role in healthy diets (eggs, poultry, dairy and fish) and the growing importance of urban markets in Ethiopia, this study had two primary objectives: (1) to describe and understand market vendors' perceptions of how ASF markets in Addis Ababa have changed over time and the reasons behind these changes; and (2) to identify challenges ASF vendors in Addis Ababa face. Given the predominant use of quantitative methods in studies on value chains, markets, and price changes, and the limited knowledge of the issues affecting urban market vendors, we adopted a qualitative approach for two main reasons. First, we sought to gain a more in-depth understanding of the challenges faced by urban market vendors than quantitative data could provide, including their perceptions and attitudes. This approach was strengthened by our use of purposive sampling frame, which allowed us to recruit a diverse sample representative of the variety of urban market vendors in Addis Ababa. Second, we sought to generate evidence that can help identify whether and what type of supply-side policies and interventions are necessary to support market vendors and to alleviate the challenges they face. The more thorough exploration and understanding of the target population, permitted by using qualitative methods, provide more detailed and nuanced information for the design and adaptation of future interventions and policies.

\section{Materials and methods}

\subsection{Study setting and context}

This study was conducted in the Kirkos and Yeka sub-cities of Addis Ababa, Ethiopia. Education levels in Addis Ababa are low: only $32 \%$ of women and $44 \%$ of men have completed secondary education or higher (Central Statistical Agency (CSA) [Ethiopia] and ICF 2016). Employment is higher among men (81\%) than women (58\%). Most Addis Ababa residents are employed in sales and services $(57 \%$ of women and $24 \%$ of men), skilled manual labour (13\% of women and $40 \%$ of men), or professional, technical, or managerial positions ( $12 \%$ of women and $18 \%$ of men). About $3 \%$ of people are employed in agriculture (Central Statistical Agency (CSA) [Ethiopia] and ICF 2016). However, urban agriculture, 
defined as fruits and vegetables production and animal husbandry within and around urban areas, accounts for approximately one-third of household income in Yeka sub-city (Mezgabu and Tolossa 2015). Urban agriculture is primarily used as a coping strategy against unemployment, poverty and high population growth (Ashebir et al. 2007). Land and water shortages are the main challenges faced by urban farmers (Mezgabu and Tolossa 2015).

Nearly one-half of Ethiopians are Orthodox Christians and one-third Muslims. The Ethiopian Church adheres to some of the strictest fasts in the world, which include 180 days of mandatory fasts for all and about 250 days for members of the clergy. Fasting includes abstention from all ASFs and fats. The 56-day Lent before Easter and the 40-day Lent before Christmas are the longest fasting periods. In addition, Orthodox Christians abstain from ASFs on Wednesdays and Fridays (Zellelew 2014).

Food systems in Ethiopia are heavily dependent on seasonality, climate, and rainfall patterns (Abegaz et al. 2018). Many parts of the country experience bimodal rains. Areas with unimodal rains between June and September observe one harvest season (meher), whereas areas with bimodal rains observe two harvest seasons (meher and belg) (Abegaz et al. 2018). Since natural pastures are the main source of animal feed, livestock production is also subject to seasonality and rain patterns (GebreMariam et al. 2013). About $40 \%$ of total food production in Ethiopia comes from the Oromia region (home of Addis Ababa), and 22\% from the Amhara region, both of which cover unimodal and bimodal rain area. Another $28 \%$ of total food production comes from the SNNP region, which is largely a unimodal rain area (Baye et al. 2019).

\subsection{Study design and sampling}

The study used a phenomenological research design (Creswell 2013), which allowed us to explore and understand the perceptions and experiences of market vendors with regard to ASF markets. First, we randomly selected two out of the 10 sub-cities in Addis Ababa. Second, within each sub-city, we used maximum variation purposive sampling to identify and recruit market vendors. This sampling strategy allowed us to examine a diverse range of participants and to gain insight from as many angles as possible (Creswell 2013). Market vendors were defined as any formal or informal individual or entity typically selling ASF and non-ASF foods and serving the catchment area. The amount and type of ASF sold were not criteria for participation. A total of 40 market vendors were identified and recruited in February 2018. Local urban agriculture unit sub-city personnel assisted in the identification and recruitment of participants. The number and type of market vendors interviewed are described in Table 1 . The categories of market vendors were identified a priori by local researchers in collaboration with the local sub-city personnel.
During the interview, market vendors were asked to describe the changes in food prices of the food commodities they sold in the past two years. This information was used to classify vendors as ASF vendors (if they reported selling any ASFs in the past two years), and non-ASF vendors (if they did not report selling ASFs in the past two years). Demographic information for each participant was not collected due to financial and logistical constraints.

\subsection{Data collection}

Data were collected through semi-structured in-depth interviews (IDIs). The IDI guide (available on request) was developed by the research team (third, fourth, fifth and sixth authors) and translated into Amharic. Each question in the IDI guide included sub-questions and probe suggestions for more information to encourage and ensure an in-depth understanding of the issues discussed by participants.

The data collection team consisted of five male and two female research assistants (RAs). All RAs had university-level education, and previous experience in agriculture- and/or nutrition-related research. Prior to the start of data collection, RAs received a three-day training on qualitative interview methods and techniques, research ethics and study objectives. During this training, RAs discussed and clarified the IDI guide, and practised conducting IDIs.

Market vendors were approached in person by RAs working in pairs. Market vendors were interviewed at their workplace. No financial or other incentives were offered. All interviews were conducted in Amharic and were audio recorded. In addition, brief field notes were taken during the interview by one of the RAs and expanded after a debriefing consultation between the two RAs at the end of each interview. RAs transcribed and translated the interviews into English.

\subsection{Data analysis}

All transcripts were analysed together. Two researchers (first and second author) analysed the data using thematic analysis. Inductive coding was used to identify emergent codes, which were then used to develop codebooks containing clear definitions for each code. Codes are words or phrases that are used to identify and record one or more passages of text that exemplify the same theoretical or descriptive idea (Gibbs 2018). Separate codebooks were created for each research objective. The first and second authors read and coded the transcripts separately. Transcripts are the written versions of the audiorecorded interviews. The initial codebooks were developed by the first author and audited by the second author. Following discussion, any code disagreements were resolved, and the final codebooks were created. The codebooks were then applied to all transcripts by the first author, who also extracted supporting quotes to highlight the main codes. Transcript 
Table 1 Type, number, and classification of the 40 vendors included in the study sample

\begin{tabular}{|c|c|c|c|}
\hline Type of interviewee & $\mathrm{N}(\%)$ & Description & $\begin{array}{l}\text { Animal source } \\
\text { food vendor }\end{array}$ \\
\hline Live animal vendor & $2(5 \%)$ & $\begin{array}{l}\text { Vendors who sells live animals (e.g., sheep, cows, goats, and chicken) on the side of the road } \\
\text { or at a designated corner where people can buy live animals to slaughter at home. }\end{array}$ & Yes \\
\hline Baltina shop & $2(5 \%)$ & $\begin{array}{l}\text { Privately-owned shop that sells raw and processed spices. Depending on the size, some } \\
\text { shops sell animal source foods, e.g., milk and yoghurt. }\end{array}$ & Yes \\
\hline Butcher & $4(10 \%)$ & $\begin{array}{l}\text { Privately-, publicly- or government-owned shop that sells meat. Separate butcher shops } \\
\text { exist for Christians and Muslims. }\end{array}$ & Yes \\
\hline Shemachoch committee & $6(15 \%)$ & Buyers' association or cooperative that sells a variety of food items. & Yes \\
\hline Dairy product vendor & $2(5 \%)$ & $\begin{array}{l}\text { Privately-owned shop that sells dairy products, e.g., milk, cheese, and butter. Dairy product } \\
\text { vendors may own dairy animals or a dairy farm themselves, or source from a local farm or } \\
\text { farmer. }\end{array}$ & Yes \\
\hline Gulit vendor & $2(5 \%)$ & Small street vendors who sell vegetables in piles. & Yes \\
\hline Street vendor & $2(5 \%)$ & $\begin{array}{l}\text { A collection of street vendors in an open-air market area who sell a variety of products, e.g., } \\
\text { live animals, spices, cereals and grains, dairy, prepared food, etc. }\end{array}$ & No \\
\hline Miller & $4(10 \%)$ & Millers primarily grind cereals and grains, but often sell cereals, grains, and legumes as well. & No \\
\hline Shop vendor & $\begin{array}{l}5 \\
(12 .- \\
5 \%)\end{array}$ & Privately-owned shops which sell a variety of products. & Yes \\
\hline Supermarket & $\begin{array}{l}3.5- \\
\%)\end{array}$ & Privately-owned modern stores that sell a variety of products. & Yes \\
\hline Urban agriculture site & $2(5 \%)$ & Urban agricultural site, typically dairy, poultry, or vegetable farm. & No \\
\hline Fruit and vegetable shop & $4(10 \%)$ & $\begin{array}{l}\text { Shops of different size and capital, which sell fruits and vegetables. Some are wholesalers, } \\
\text { others are distributers. }\end{array}$ & No \\
\hline Vegetable farmer & $2(5 \%)$ & $\begin{array}{l}\text { Farmers who sell vegetables. Different in size, capital, and function (wholesaler or } \\
\text { distributor). }\end{array}$ & No \\
\hline
\end{tabular}

coding and analysis was conducted using NVivo Version 12 (QSR International Pty Ltd. 2018). The researchers who analysed the data were not involved in the development and implementation of the study and IDI guides, or any aspects of data collection.

We hypothesized that non-ASF market vendors may help provide a more nuanced and objective view of the changes and challenges faced in ASF markets. However, after analysing the data, we observed that ASF and non-ASF vendor responses were similar, and the themes we identified were aligned across the two types of vendors. Therefore, we present results for ASF and non-ASF vendors together.

To examine the relations between the codes identified under each objective and across both objectives, we assigned all identified codes into one of the following five nonoverlapping categories: (1) biophysical and environmental factors, (2) innovation, technology, and infrastructure factors, (3) political and economic factors, (4) socio-cultural factors, and (5) demographic factors (HLPE 2017).

\section{Results}

We interviewed 40 respondents, representing 13 types of formal and informal, ASF and non-ASF market vendors
(Table 1). The main ASFs available in the study locations in the past two years were butter, cheese, chicken, eggs, fish, meat, milk, and yogurt.

\subsection{Changes in ASF markets and reasons for changes}

We identified 13 emergent codes describing recent changes in ASF markets in Addis Ababa, and the reasons for these changes. Quotes supporting each code are presented in Table 2.

When asked whether prices have increased, decreased, or stayed the same over the past two years, all market vendors unequivocally stated that prices have increased for all locally available ASFs (Table 2, Quote 15). Reported price increases ranged from $\sim 15 \%$ for eggs to $\sim 70 \%$ for butter. Many vendors also reported observing large fluctuations in ASF prices (Table 2, Quote 14), especially for seasonally-dependent ASFs such as fish and meat.

Consistently mentioned reasons for the perceived ASF price increases and fluctuations were supply shortages, consumer demand and preferences, socio-economic status (SES), and input costs. Market vendors reported experiencing both general supply shortages (Table 2, Quote 18) and seasonalityrelated shortages. For example, fish supply was reportedly low during the winter (June-mid September), and some dairy products were less available during the livestock breeding 
Table 2 Supporting quotes for the main codes identified with respect to changes in the markets for animal source foods and the reasons for these changes

\begin{tabular}{|c|c|c|c|}
\hline Codes & Supporting quotes & Respondent & $\begin{array}{l}\text { Quote } \\
\text { number }\end{array}$ \\
\hline $\begin{array}{r}\text { Consumer } \\
\text { demand }\end{array}$ & $\begin{array}{l}\text { With regard to meat, there is dramatically increasing demand for the meat product even if its price is } \\
\text { increased [for] raw meat (Kurt), tibs, and kikile in the restaurant. }{ }^{\text {a }}\end{array}$ & $\begin{array}{l}\text { ID10 Shemachoch } \\
\text { committee }\end{array}$ & 1 \\
\hline \multirow[t]{2}{*}{$\begin{array}{l}\text { Consumer } \\
\text { preferences }\end{array}$} & $\begin{array}{l}\text { As it's known, the price of meat is increasing. It is sold at } 300 \text { birr per kg. To avoid this [high price], } \\
\text { people are choosing their favourite foods as non-meat foods. }{ }^{\text {b }}\end{array}$ & $\begin{array}{l}\text { ID01 Live animal } \\
\text { vendor }\end{array}$ & 2 \\
\hline & People usually prefer less price rather than the quality of the meat. & ID07 Butcher & 3 \\
\hline \multicolumn{4}{|c|}{ Demographic factors } \\
\hline Migration & $\begin{array}{l}\text { The number of the people living in the country is highly increasing. The number of people who } \\
\text { migrat[e] to the city is increasing dramatically. }\end{array}$ & ID06 Butcher & 4 \\
\hline $\begin{array}{l}\text { Population } \\
\text { growth }\end{array}$ & $\begin{array}{l}\text { On the other hand, the increment in the population also makes [an] impact on the market because of } \\
\text { children's common use of products from animal source and this is because it is recommended by } \\
\text { health officers. }\end{array}$ & $\begin{array}{l}\text { ID33 Urban } \\
\text { agriculture site }\end{array}$ & 5 \\
\hline Food services & $\begin{array}{l}\text { Market for animal source food in the restaurant like meat, dairy and egg are continuously increasing. } \\
\text { Even sometimes the supply of these food items from producer is not as per the demand from the } \\
\text { customers (which is less). }\end{array}$ & $\begin{array}{l}\text { ID10 Shemachoch } \\
\text { committee }\end{array}$ & 6 \\
\hline \multicolumn{4}{|l|}{ Government } \\
\hline $\begin{array}{l}\text { Foreign } \\
\text { exchange }\end{array}$ & $\begin{array}{l}\text { The government has increased the country foreign currency. The Ethiopian money is inflated } \\
\text { seriously. The recent devaluation of Ethiopian money is among the basic reasons which } \\
\text { exacerbate the price increment. }\end{array}$ & ID06 Butcher & 7 \\
\hline Free market & $\begin{array}{l}\text { The policy of free market economy is also a factor for price changes as it is not controlled by } \\
\text { [the] Government. }\end{array}$ & $\begin{array}{l}\text { ID12 Shemachoch } \\
\text { committee }\end{array}$ & 8 \\
\hline Taxes & $\begin{array}{l}\text { Before there was no tax but now, we pay tax to the government. Due to this reason [paying tax], } \\
\text { price has increased in every item. }\end{array}$ & ID05 Butcher & 9 \\
\hline Holidays & $\begin{array}{l}\text { For example, the holiday season has a significant difference on both supply and price. During the } \\
\text { holiday season, consumers' demand is increasing, and it is our profitable time. }\end{array}$ & $\begin{array}{l}\text { ID01 Live animal } \\
\text { vendor }\end{array}$ & 10 \\
\hline Cost of inputs & $\begin{array}{l}\text { I have made some changes on the price to cover the cost of foods for animals since the cost of the } \\
\text { foods for animal are increasing from day to day. }\end{array}$ & $\begin{array}{l}\text { ID13 Dairy product } \\
\text { vendor }\end{array}$ & 11 \\
\hline $\begin{array}{l}\text { International } \\
\text { trade }\end{array}$ & $\begin{array}{l}\text { Exporting meat and meat products and cattle to the foreign market has also played its own role for } \\
\text { the price increment. }\end{array}$ & ID06 Butcher & 12 \\
\hline Political climate & $\begin{array}{l}\text { The price variation or fluctuation occurred due to the instability in the country. I bring many of my } \\
\text { commodities from the surrounding towns around Addis Ababa. Since the road will be closed and } \\
\text { it is hard to access transportation, most of my customers found it hard to send the commodity to } \\
\text { me. This is the reason that made the price fall and rise every time. }\end{array}$ & ID03 Baltina shop & 13 \\
\hline \multicolumn{4}{|l|}{ Prices } \\
\hline Fluctuation & $\begin{array}{l}\text { I think the fluctuation in the price of goods is caused by shortage of supply. When there is shortage } \\
\text { the item price will increase. }\end{array}$ & ID04 Baltina shop & 14 \\
\hline Increase & $\begin{array}{l}\text { There has been an enormous food price change during the past two years. Even if there has been } \\
\text { enormous price rise over the past two years, this year the price increment is unbelievable and } \\
\text { unique. }\end{array}$ & ID06 Butcher & 15 \\
\hline \multirow{2}{*}{$\begin{array}{l}\text { Socio-economic } \\
\text { status }\end{array}$} & Consuming dairy products is also the way to show improved life status. & ID06 Butcher & 16 \\
\hline & $\begin{array}{l}\text { Meat is not scarce on [the] market. But its higher price makes it difficult for lower economic class } \\
\text { society to buy and eat. }\end{array}$ & ID08 Butcher & 17 \\
\hline Supply & Generally speaking, I think there is not enough supply. & $\begin{array}{l}\text { ID01 Live animal } \\
\text { vendor }\end{array}$ & 18 \\
\hline Seasonality & $\begin{array}{l}\text { In May, we have shortage of cattle in the market. And also, since June is a fasting month, they do not } \\
\text { bring [cattle] in the market. May is fully non-profitable season. There is shortage on the avail- } \\
\text { ability of cattle in the market as well as the price is also high. }\end{array}$ & ID07 Butcher & 19 \\
\hline Transportation & $\begin{array}{l}\text { And the transpiration cost has increased due to increment of dollar exchange. Therefore, because of } \\
\text { the transportation cost, the price has increased. }\end{array}$ & ID07 Butcher & 20 \\
\hline
\end{tabular}

Codes are words or phrases that are used to identify and record one or more passages of text that exemplify the same theoretical or descriptive idea. Supporting quotes are passages taken directly from the translated transcripts that provide examples of the text to which the codes were applied. Next to each quote listed, the corresponding "Respondent" column provides information on the type of vendor from whom the quote was taken and their respondent ID number, which was a unique number given to each interviewee. The quote number enumerates the quotes presented in the table to allow easy references between the article text and tables.

${ }^{a}$ Tibs and kikile are types of Ethiopian meat stews

${ }^{\mathrm{b}} 1$ Ethiopian Birr is equivalent to 3 US cents 
period (May-June) (Table 2, Quote 19). The rising cost of inputs (e.g., animal feed) was a salient code explaining the rising price of ASFs, particularly meat (Table 2, Quote 11). Consumer preferences and demand also contributed to reported price increases. Market vendors' perceived consumer preferences shifting from domestic to foreign products, and from generic to branded products, which contributed to both changes in sale volumes and prices. A dramatic increase in ASF demand over time was reported (Table 2, Quote 1), which one market vendor explained was because ASFs were heavily promoted by healthcare providers for use among young children. Finally, the role of consumer SES in ASF markets emerged as a code. Some market vendors reported ASF consumption was a way of demonstrating higher SES (Table 2, Quote 16), which increased ASF demand and prices, whereas others perceived low SES as a factor suppressing ASF demand (Table 2, Quote 17).

Less salient codes that emerged as reasons for changes in ASF markets included demographic factors, food services, government policies, holidays, international trade, political climate, and transportation. With respect to demographic factors, market vendors recognized the role of rural-urban migration (Table 2, Quote 4) and high urban population growth (Table 2, Quote 5) as determinants of rising ASF demand and prices. The food services, e.g., restaurants and other vendors of prepared foods, also contributed to rising ASF demand and prices (Table 2, Quote 6). Both religious and nonreligious holidays were also mentioned by market vendors as determinants of ASF prices. For example, religious fasting influences the demand for and prices of all ASF foods, whereas wedding ceremonies drive the demand for luxury foods, such as cheese. Among the government policies that have reportedly affected ASF prices, market vendors mentioned foreign exchange, free markets, and taxation. Recent devaluation of the Ethiopian Birr (ETB) was identified as a major reason for changing prices (Table 2, Quote 7) and input costs (e.g., animal feed, transportation, etc.). The foreign exchange code was related to the international trade code. Significant increases were noted by market vendors in the prices of imported foods and food inputs. International exports were also linked to the observed price increment (Table 2, Quote 12). In addition, the free market policy adopted by the Ethiopian government was given as an explanation for rising ASF prices by several market vendors (Table 2, Quote 8). Finally, political climate, i.e., regional instability, contributed to rising prices primarily by increasing the difficulty and cost of transportation (Table 2, Quote 13). Rising transportation costs were also related to foreign exchange (Table 2, Quote 20), as well as seasonal difficulties in accessing roads (e.g., using dirt roads during the rainy season).

Product-specific codes with respect to market changes and the reasons for these changes were also identified. Whereas the prices for all ASFs increased, and especially the prices of meat and dairy products, demand changed differentially. Several market vendors reported low-to-no demand for fish, and infrequent demand for cheese, which is primarily consumed at weddings and other social ceremonies. In contrast, meat and dairy had strong, continuously growing demand:
"Before, we were selling one ox meat in a week but now we sell one ox meat in four days." (ID05 Butcher)
"The level of sales of milk has increased dramatically. The reason for this is that [the] number of customers taking [milk] for their children, and more often for adults, are outnumbered. So, increasing the community's consumption of dairy increased my sales volume." (ID13 Dairy product vendor)

No unique reasons for product-specific market changes emerged in addition to the ones discussed in this section. Supply shortages were most frequently reported for butter, fish, and yogurt.

\subsection{Challenges faced by ASF vendors}

With respect to challenges faced by ASF vendors, we identified 11 codes, supporting quotes for which are presented in Table 3. These codes emerged from both ASF and non-ASF vendor responses. Supply problems, religious fasting, consumer demand, price increases and fluctuations, transportation, market infrastructure, and government policies were all among the more pressing challenges market vendors reported facing. A variety of supply problems related to shortages and continuity (Table 3, Quote 19) were described by vendors. Seasonality also posed a challenge, particularly with respect to meat and dairy products. For example, vendors reported less availability of meat during the livestock breeding period (May-June), and longer time for livestock to reach market weight during colder months (Table 3, Quote 20). Religious fasting and consumer demand also posed substantial challenges. Many vendors reported few or no customers during fasting times (Table 3, Quote 18) and one even reported closing for the duration of the fast. Likewise, many vendors commented on fluctuations in consumer demand, with increased demand during holidays (Table 3, Quote 3), and lower demand during other parts of the year. Price increases and fluctuations also posed a challenge such that market vendors had to change prices to smooth their profits throughout the year (Table 3, Quote 16). Multiple aspects of transportation emerged as critical challenges. For example, seasons affected road accessibility (Table 3, Quote 21). Likewise, political climate and instability in parts of the country made it difficult to transport foods to Addis Ababa. The noticeable increase in the cost of transportation also emerged as a challenge.

Market infrastructure was another crucial code we identified. First, how the market was organized played a role in what 
Table 3 Supporting quotes for the main codes identified with respect to challenges faced by vendors of animal source foods

\begin{tabular}{llc}
\hline Codes Supporting quotes & $\begin{array}{c}\text { Respondent } \\
\text { Quote } \\
\text { number }\end{array}$ \\
\hline
\end{tabular}

Animal services

Animal We slaughtered ox by first paying for veterinary doctor for checking in kera (Regional ox slaughter). But others

ID07 Butcher $\quad 1$

health do not check the cattle's health status and they just slaughtered the cattle at their house. Therefore, since these people sell meat for less price and we sell with high price, our customers do not buy us. People usually prefer less price rather than the quality of the meat.

Veterinarians And again, we have a problem of veterinaries, there is no health care provider/veterinaries. Our animals are dying, there are government employees for this purpose, but they are not working properly which creates a problem to us.

Consumer For example, the holiday season has a significant difference on both supply and price. During the holiday demand season, consumers' demand is increasing, and it is our profitable time.

Government In addition, we want to export sheep meat and other wastages to foreign countries, but we couldn't get the license.

Foreign It is because the dollar has increased. Since necessary inputs and food for the animals come from industries and exchange abroad in dollars, it gets expensive.

Free market Issuance of free market: the only vendors who use this chance properly are merchants, where because there are no price controls and monitoring they can set whatever price they want on the market.

ID02 Live animal 2 vendor

ID01 Live animal 3 vendor

ID30 Supermarket 4

ID14 Dairy 5 product vendor

ID33 Urban agriculture site

Price ceilings As the price of livestock is expensive and there is free market policy, there is high increment in the price of meat. Before three years, the Government interfered and declared not to sell meat above $110 \mathrm{birr} / \mathrm{KG}$. But this time, that has been forgotten and the price has increased to 300 for beef meat and 350 for goat meat per Kg. ${ }^{\text {a }}$

Taxes In addition, as I increased my business, I am afraid that the tax rate will increase.

Inputs

The reason they give me for the price increment is [that] the farmers increased the price on them, the farmers are now us[e] better technology.

ID13 Dairy 8 product vendor

\section{Costs}

Let's take milk as an example. To get milk it's necessary to feed the cow well in order for the cow to give good

D13 Dairy product vendor milk. The cow needs food, therefore because of the price to provide a balanced diet for the cow, it is expensive, so it needs a lot of money. Seasonality Seasons have big influence on the food availability. For example, if you take the dry season, which is commonly
called Bega (winter), since it is impossible to widely access water and animal food in lowland areas of Ethiopia, it affects the availability of meat products on the market. Even during summer season, the same happens to the highland areas of the country.

Market infrastructure Brokers

The main reasons for price increments are [the] rise in house rent and the taxation by the government even of food items.

There is a variation in the chain of sale hierarchy starting from the producer to the venders and the merchants. This means the brokers for their business will increase the price of the product to get their commission fees.

Working space

For example, if I also have hen production, I would be happy, but I can't. I want to have animal feeds processer, but I didn't due to no animal feed processers. If I can, it will be useful for others too. Why I can't do it? There is no suitable place. The big problem is the place of working. Because of capital/money, you have a chance to take a loan from the government. The problem is not having place.

Political climate

Prices their products to the market. Since most people live in [the] city, if they cannot go and buy their daily
groceries, it is obvious that they will struggle.

Prices

Profits

Religious fasting

Supply

Seasonality Actually, in summer season, there is decrement in ox availability. Oxen
warm places. Due to this the availability of the oxen may decrease.

The reason for [the] price increment is in holidays the community consuming volume is high. As mercha have a loss in fasting seasons. We need to balance our profit and we increased the price a little bit.

ID06 Butcher

30 Supermarket We are not selling it [goat met

Since many of my customers are Orthodox Christians, on holidays especially during Christmas and Easter fasting, the number of my customers are very little or almost no customer. Only milk is available during these periods. Even the milk is used by those who have kids.

Sometimes there is discontinuation of milk supply. Since there is no one who could supply shola milk, I do not ID32 Supermarket 19 purchase.

Transportation The summer is a very wet time. Due to mud, food items cannot be transported to the city. This is because the ID06 Butcher road problem is very high in the country.

Codes are words or phrases that are used to identify and record one or more passages of text that exemplify the same theoretical or descriptive idea. Supporting quotes are passages taken directly from the translated transcripts that provide examples of the text to which the codes were applied. Next to each quote listed, the corresponding "Respondent" column provides information on the type of vendor from whom the quote was taken and their respondent ID number, which was a unique number given to each interviewee. The quote number enumerates the quotes presented in the table to allow easy references between the article text and tables

${ }^{\text {a }} 1$ Ethiopian Birr is equivalent to 3 US cents 
ASF products market vendors offered and how much they charged for them. One supermarket vendor reported:

"Additionally, nearest to my market there are different shops and a big market, the situation now is to get a lower price, customers are going there to get a lower price." (ID31 Supermarket)

Another vendor considered closing their business due to the increasing number of ASF vendors and increasing competition in the area. Second, rising rents posed a challenge for some vendors (Table 3, Quote 12). Third, several vendors mentioned their interest in expanding their business and the difficulty in finding enough working space to do so (Table 3, Quote 14). Fourth, the presence of brokers or middlemen between producers and vendors was a significant challenge mentioned by many of the vendors we interviewed. Brokers exert much influence in local markets, raising their commissions which leads to price increases (Table 3, Quote 13) or hiding products to generate shortages and price hikes. Though it remains unclear how exactly the latter affects ASF vendors given that ASFs are typically consumed fresh.

Lastly, government policies related to foreign exchange, free markets, price controls and taxation emerged as challenges. Vendors reported that foreign exchange policies that decreased the value of the ETB compared to the United States dollar (USD) led to large increases in the price of inputs (Table 3, Quote 5). Similarly, the free market policy endorsed by the Ethiopian government reportedly allows market participants to charge whatever price they want (Table 3, Quote 6), which has contributed to the price increases observed by ASF vendors and has affected their competitiveness and ability to cater to their clients. Several vendors described a price ceiling policy on the price of meat. While one vendor described the policy as "forgotten" (Table 3, Quote 7), another vendor expressed fear that not displaying stamps with prices below the official price ceiling could lead to repercussions from the local authorities. Finally, vendors reported difficulties in obtaining export licenses (Table 3, Quote 4), and fear of increasing tax rates (Table 3, Quote 8).

In addition to these prominent codes, several less pressing challenges also emerged: the lack of proper animal services (Table 3, Quotes 1 and 2), low profit margins (Table 3, Quote 17), the cost and seasonal availability of inputs (Table 3, Quotes 9-11), and political climate (Table 3, Quote 15). With respect to individual ASFs, supply shortages plagued all dairy products, while seasonality reduced the availability of meat through seasonal availability of animal feed and livestock breeding periods. No challenges emerged regarding chickens or eggs:
"Chickens always throw eggs, and we always provide chickens well suited for food." (ID01, Live animal vendor)

\subsection{Relations between themes}

Figure 1 presents a schema of the relations between the different categories of codes under each objective and across the two objectives. Seven codes in four (out of five) categories of factors emerged as common to both objectives: supply issues, input costs, consumer demand, government policies, prices, political climate, and transportation (Fig. 1). Codes within categories were closely related. For example, within the political and economic factors category, prices were related to government policies, specifically taxation and a free market policy, which were perceived as drivers of the ASF price increment and as challenges to expanding business. In addition, codes were related across categories, e.g., foreign exchange policies were related to input and transportation costs, which in turn were related to each other.

Relations emerged between objective-specific codes within categories of factors. For example, consumer demand, which emerged as a code common to both study objectives, was related to other socio-cultural factors which were perceived to drive the ASF price increment (e.g., consumer preferences, SES, holidays and food services) or were perceived as challenges by ASF vendors (e.g., religious fasting). Finally, demographic factors emerged as the only category unique to our first objective.

\section{Discussion}

We used qualitative methods to examine market vendors' perceptions of how ASF markets in Addis Ababa have changed over time and the reasons behind these changes, and to identify challenges faced by ASF vendors. With respect to our first objective, we found that all ASF prices have increased dramatically in the past two years, and that market vendors largely attributed this increase to supply shortages, consumer preferences and demand, SES, and input costs, among other less prominent causes. Regarding our second objective, our findings indicate that supply issues, religious fasting, consumer demand, price increases and fluctuations, transportation, market infrastructure, and government policies are among the main challenges faced by ASF vendors in Addis Ababa.

Our findings that ASF prices increased over time are supported by a growing body of literature on the rising prices of ASFs, and food commodities more broadly, in Ethiopia (Abegaz et al. 2018; Bachewe et al. 2017; Nandy et al. 2016; Yu and Shimokawa 2016). National statistics reflect the price increment we observed for some ASFs in Addis 


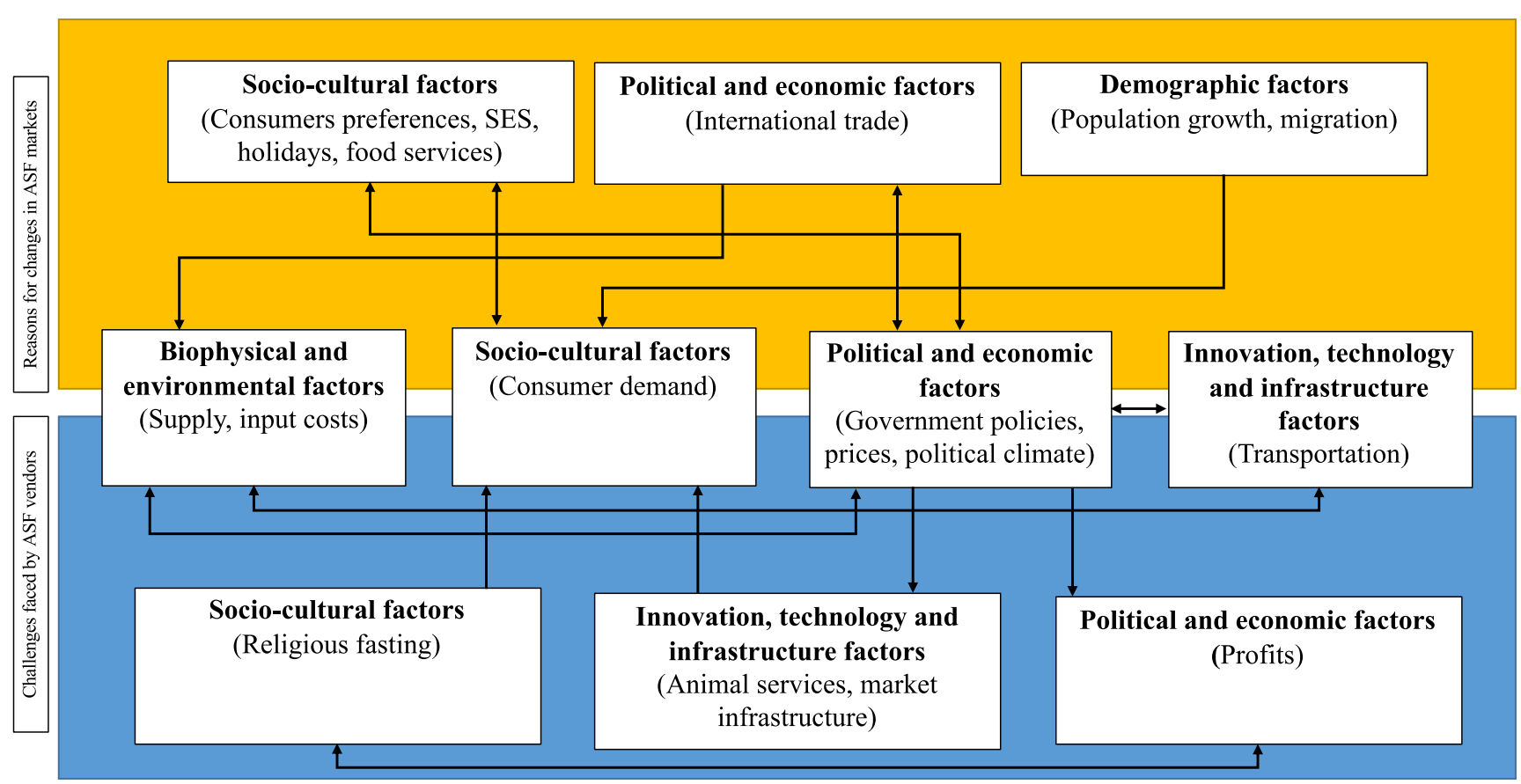

Fig. 1 Schema representing the relations between the categories of codes identified under each objective

Ababa. For example, the price of chicken (ETB/t) increased by $20 \%$ from 2014 to 2015 (Food and Agriculture Organization of the United Nations 2019), and the price of meat increased by $400 \%$ from 2005 to 2013 ( $\mathrm{Yu}$ and Shimokawa 2016). However, the price of eggs (ETB /t) increased by $6 \%$ between 2016 and 2017 , while the price of whole cow milk (ETB /t) increased by only $2 \%$ from 2017 to 2018 (Food and Agriculture Organization of the United Nations 2019). The perceived reasons for the ASF price increment reflect larger trends in Ethiopia. For example, with respect to high input costs, other studies have shown that the prices of feed and compound feed have increased between 11 and $16 \%$ annually over the past five years (Bediye et al. 2018). Consumer demand for ASFs has also been increasing in all regions in Ethiopia (Abegaz et al. 2018).

With respect to our second objective, we confirmed previously identified challenges in livestock markets (GebreMariam et al. 2013): lack of animal services, supply problems, high input costs, broker price influence, and high transportation cost. Many of the challenges identified in the live cattle and beef value chains in Ethiopia (e.g., lack of sufficient and quality animal feed, lack of veterinary services, and weak service infrastructure) have persisted for decades (GebreMariam et al. 2013). Our findings suggest that these challenges affect the value chain beyond production, i.e., directly influence market vendors and consumers. Ethiopia's latest Agriculture Extension Strategy aims to eliminate many of these challenges. For example, climate smart agricultural interventions promoted by the Strategy focus specifically on improving livestock management, including veterinary services, grazing capacity and forage technologies (Ministry of Agriculture and Natural Resources 2017). Likewise, there are plans to expand coverage of animal clinical services and vaccination to $85 \%$ and $95 \%$, respectively (National Planning Commission 2016). Studies among rural poultry farmers have shown that farms understand and appreciate the benefits of vaccinations and are willing to pay for vaccination services (Terfa et al. 2015). In addition, Ethiopia's 2015-2020 Livestock Master Plan prioritizes interventions to improve the quantity and quality of animal feed such as rehabilitation of range and pasture lands, tax incentives and subsidized rates for leasing land for animal production, establishment of private-sector flour and oil mills to produce additional feed, and removal of double-imposition of value added taxes and excessive customs duties on feed ingredients, among other interventions aimed to transform the livestock sector (Shapiro et al. 2015). Together these interventions will help address the multiple bottlenecks and challenges along the different livestock value chains.

In addition to confirming known challenges faced by ASF market vendors, we uncovered additional barriers primarily related to market infrastructure and government policies. High rent prices and tax rates reportedly affected profit margins, whereas lack of working space, licensing and taxation prevented vendors from expanding their businesses. Importantly, investment capital did not emerge as a barrier to business expansion and market growth, but rather as a facilitator. These findings indicate that government policies to provide adequate financing to micro and small enterprises outlined in the Growth Transformation Plans have been 
effective (National Planning Commission 2016). However, other government policies around foreign exchange, free markets, price ceilings, licensing and taxation undermined the optimal operation of ASF markets. Surprisingly, ASF vendors still adhered to meat price controls, which were only enforced in the first half of 2011, about seven years before data collection.

Several limitations of our study are of note. First, our findings are specific to Addis Ababa and may not be generalizable to other urban or rural contexts in Ethiopia, or other SSA contexts. Second, we interviewed market vendors based on their availability and willingness to participate in the study, which is a potential source of bias. Self-selection may have biased our results in favour of those perceiving or experiencing more challenges related to ASFs. Third, we did not quantitatively assess ASF price changes in Addis Ababa over time. It is possible that market vendors' perceptions of ASF price changes and the reasons behind these changes do not correspond to actual market changes. National statistics showed a striking increase only in the price of chicken and meat, but not in the price of eggs or milk (Food and Agriculture Organization of the United Nations 2019; Yu and Shimokawa 2016). It remains unclear whether vendors exaggerated the price increment, or whether national statistics are too crude to capture price changes for small, local vendors. Likewise, we collected no information on the actual market structure and infrastructure, or policy and consumer environments. Therefore, we are unable to gauge the extent to which perceived challenges correspond to existing barriers.

Despite these limitations, our study highlights a wide range of opportunities to address challenges faced by ASF vendors, and to optimize ASF markets in Addis Ababa. First, improving storage facilities (e.g., sufficient refrigeration space with permanent electricity supply) along the value chain can help smooth supply throughout the year and reduce vendors' season and climate dependability. However, given the multitude of public and private sector actors that will likely need to be involved in ensuring quality storage infrastructure and meeting increased electricity demand, joint solutions through public-private partnerships will likely be necessary. Who absorbs the start-up and recurrent costs of improved storage infrastructure will depend on individual ASF supply chains, their length and the number of actors involved. Ethiopia's latest Agriculture Extension Strategy has already laid out strategies and interventions to promote commodity-specific value chain-based platforms, which aim to promote dialogue, develop and strengthen partnerships, and enhance collective actions. These actions will help improve linkages and build trust between value chain actors at the national and regional levels (Ministry of Agriculture and Natural Resources 2017) and build the collaborative environment necessary to improve storage infrastructure along ASF value chains. In addition, the development of adequate storage infrastructure beyond production and along the entire ASF value chains can be prioritized in the next Livestock Master Plan. The current 20152020 Livestock Master Plan prioritizes storage infrastructure and capacity primarily related to livestock breeding and animal feed. Although the Plan recommends policy actions to enforce the use of refrigerated transportation of meat products, it makes no other policy or intervention recommendations related to cold storage (Shapiro et al. 2015).

Second, although this would require long-term government commitment and investment, strategic planning and careful use and management of limited urban land, infrastructure challenges should be urgently addressed, specifically those related to transportation and physical market infrastructure. Although roads around Addis Ababa have improved over the past three years, improvements have not yet trickled down to market vendors, as evidenced by the transportation challenges voiced by vendors. Likewise, the residential real estate market in Addis Ababa has grown in the past decade, converting urban agricultural land into residential areas, and thus lengthening the supply chain and increasing transportation and storage needs, as well as increasing consumer demand.

Third, government efforts and commitment to establish an enabling environment for healthy and sustainable diets should be strengthened. Economic policies and programs should be instituted to help protect small market vendors from the adverse effects of foreign exchange policies. In addition, tax reforms supporting small business owners may be necessary. Small businesses bear the highest effective tax burden in Ethiopia, primarily due to high compliance costs and strict reporting requirements (Mascagni and Mengistu 2019). Fourth, marketbased supply-side interventions and policies should adopt a long-term view accounting for the rapid demographic changes Ethiopia is experiencing and serving the changing dietary needs of a growing urban population in Addis Ababa.

Finally, our findings indicate that although previous dietary diversification efforts were thwarted by supply-side factors (Ethiopian Public Health Institute 2013), future efforts will likely require adaptation for different religious and social groups. For example, among Orthodox Christians, dietary diversification efforts may need to promote plant-based sources of protein (e.g., legumes and nuts) more heavily than ASFs, or engage the clergy to help reduce the stigma associated with consuming ASFs during fasting periods in order to encourage ASF consumption among pregnant women and children. In addition, our findings can help inform Ethiopia's national food-based dietary guidelines, which are currently under development (Bekele et al. 2019). They shed light on whether global dietary recommendations and guidelines focused on protein intake, similar to those made by the EAT-Lancet Commission (Willett et al. 2019), can realistically be adopted to promote healthy and sustainable urban diets in Ethiopia. Given the supply shortages and low consumer demand for fish, and the increasing consumer demand for red meat, our 
findings suggest that implementation of the EAT-Lancet Commission ASF recommendations would not be culturally appropriate or feasible in this context. Moreover, the EATLancet reference diet costs over $70 \%$ of daily household per capita income and is thus unaffordable for most Ethiopians. ASFs specifically account for over one-third of the total cost of the EAT-Lancet diet in low-income countries such as Ethiopia (Hirvonen et al. 2020). Reductions in ASF consumption may provide limited health and environmental benefits in a population where ASF intake is already low among most of the population (Ethiopian Public Health Institute 2013). While some populations (e.g., wealthier or urban consumers) may benefit from reductions in red and/or processed meat consumption, other consumers who are below their recommended intakes of micronutrients like iron and vitamin B12 may benefit from increasing their meat consumption. Similarly, Ethiopia's strategic focus on transforming traditional livestock production into a climate smart industry (Ministry of Agriculture and Natural Resources 2017; National Planning Commission 2016) suggests that the environmental benefits of switching away from ASFs may be small. Overall, our findings demonstrate that locally developed dietary recommendations and guidelines that consider consumer preferences, religious and social norms, local and regional supply chains and food system, and the availability, accessibility and affordability of different animal- and protein-source foods may be more likely to result in healthy and sustainable urban diets than broad recommendations or guidelines based on global evidence.

\section{Conclusion}

In conclusion, we found that all market vendors agreed that all ASF prices in Addis Ababa have increased over the past two years due to supply shortages, high input costs, and consumer demand, preferences, and SES. The challenges vendors faced were related to supply problems, religious fasting, consumer demand, price increases and fluctuations, transportation, market infrastructure, and government policies. Although some policies to address these challenges are already in place in Ethiopia's current strategic plans, we identified several areas where supply-side interventions and policies are still needed. Future interventions and policies should specifically focus on building cold storage infrastructure, improving the physical infrastructure of markets, and tax reform to support micro and small businesses. In addition, future strategic planning should better incorporate market vendors into value chainbased solutions. Collaborative, multisectoral and multidisciplinary approaches are necessary to optimize urban ASF markets.
Acknowledgements The authors would like to acknowledge the study participants and data collectors for their time and for making the study possible.

Authors' contributions LB conceptualized the analyses presented in this paper. AWT, YB, CRC and WF designed and implemented the overall study. AWT and YB led the data collection activities. LB and SP led the data analyses. LB drafted the manuscript. All authors read and approved the final manuscript and contributed to the intellectual content. LB had final responsibility for submitting this article for publication.

Funding This work was supported by the United Kingdom Economic and Social Research Council (ESRC) and Department for International Development (DFID) Joint Fund for Poverty Alleviation Research (grant number: ES/R002118/1).

Data availability De-identified interview scripts and codebooks are available upon request from the corresponding author.

\section{Compliance with ethical standards}

Conflict of interest The authors declare no conflicts of interest.

Ethical approval The study was performed in line with the principles of the Declaration of Helsinki. Ethical approval was received by the institutional review boards of the Addis Continental Institute of Public Health (reference number ACIPH/IRB/001/2018) and the Harvard T.H. Chan School of Public Health (reference number: IRB17-1825).

Consent to participate Written informed consent was obtained from each participant. Participants were asked to provide additional oral consent for audio recording the interviews.

Code availability De-identified interview scripts and codebooks are available upon request from the corresponding author.

\section{References}

Abegaz, G. A., Hassen, I. W., \& Minten, B. (2018). Consumption of Animal-source Foods in Ethiopia: Patterns, Changes, and Determinants. ESSP Working Paper 113. Washington, D.C. and Addis Ababa.

Alemayehu K 2011: Value chain assessment of beef cattle production and marketing in Ethiopia: Challenges and opportunities of linking smallholder farmers to the markets. Livestock Research for Rural Development. Volume 23, Article \#255

Ashebir, D., Pasquini, M., \& Bihon, W. (2007). Urban agriculture in Mekelle, Tigray state, Ethiopia: Principal characteristics, opportunities and constraints for further research and development. Cities, 24(3), 218-228.

Bachewe, F. N., Minten, B., \& Yimer, F. (2017). The rising costs of animal-source foods in Ethiopia: Evidence and implications. ESSP Working Paper 108. Washington, D.C. and Addis Ababa.

Baye, K., Hirvonen, K., Dereje, M., \& Remans, R. (2019). Energy and nutrient production in Ethiopia, 2011-2015: Implications to supporting healthy diets and food systems. PLoS One, 14(3), e0213182.

Bediye, S., Nemi, G., \& Makkar, H. (2018). Ethiopian feed industry: current status, challenges and opportunities. Broadening Horizons, 
50, 1-7. https://www.feedipedia.org/sites/default/files/public/BH 050 feed_industry_ethiopia.pdf. Accessed 27 Sept 2019.

Bekele, T. H., de Vries, J. J., Trijsburg, L., Feskens, E., Covic, N., Kennedy, G., \& Brouwer, I. D. (2019). Methodology for developing and evaluating food-based dietary guidelines and a healthy eating index for Ethiopia: A study protocol. BMJ Open, 9(7), e027846.

Benfica, Rui., \& Thurlow, James. (2017). Identifying priority valuechains in Ethiopia. ESSP Working Paper 110. Washington, D.C. and Addis Ababa, Ethiopia: International Food Policy Research Institute (IFPRI) and Ethiopian Development Research Institute (EDRI). http://ebrary.ifpri.org/cdm/ref/collection/p15738coll2/id/ 131413. Accessed 31 Aug 2019.

Birhane, T., Shiferaw, S., Hagos, S., \& Mohindra, K. S. (2014). Urban food insecurity in the context of high food prices: A community based cross sectional study in Addis Ababa, Ethiopia. BMC Public Health, 14(1), 680.

Central Intelligence Agency (2019). The World Factbook. Washington, DC. https://www.cia.gov/library/publications/the-world-factbook/ index.html. Accessed 15 July 2019.

Central Statistical Agency (CSA) [Ethiopia], \& ICF (2016). Ethiopia Demographic and Health Survey 2016. Addis Ababa, Ethiopia, and Rockville, Maryland, USA: CSA and ICF.

Creswell, J. W. (2013). Qualitative inquiry and research design: Choosing among five approaches (3rd ed.). Los Angeles: Sage Publications.

Ethiopian Public Health Institute. (2013). Ethiopia National Food Consumption Survey (p. 95pp). https:/ephi.gov.et/images/pictures/ NationalFoodConsumptionSurveyReport_Ethiopia.pdf. Accessed 2 May 2019.

Food and Agriculture Organization of the United Nations. (2019). FAOSTAT statistical database. Rome: FAO.

GebreMariam, S., Amare, S., Baker, D., \& Solomon, A. (2010). Diagnostic study of live cattle and beef production and marketing: Constraints and opportunities for enhancing the system. Seattle, WA(USA): Bill \& Melinda Gates Foundation and Addis Ababa, Ethiopia: Ethiopian Agricultural Transformation Agency.

GebreMariam, S., Amare, S., Baker, D., Solomon, A., \& Davies, R. (2013). Study of the Ethiopian live cattle and beef value chain. ILRI Discussion Paper 23. Nairobi.

Gebru, M., Remans, R., Brouwer, I., Baye, K., Melesse, M. B., Covic, N., et al. (2018). Food systems for healthier diets in Ethiopia: Toward a research agenda. IFPRI discussion paper 1720. Washington, DC: International Food Policy Research Institute (IFPRI).

Gibbs, G. R. (2018). Analyzing Qualitative Data (2nd ed.). Thousand Oaks: SAGE Publications Ltd.

Hill, R. V., \& Porter, C. (2017). Vulnerability to drought and food Price shocks: Evidence from Ethiopia. World Development, 96, 65-77.

Hirvonen, K., Bai, Y., Headey, D., \& Masters, W. A. (2020). Affordability of the EAT-lancet reference diet: A global analysis. The Lancet Global Health, 8(1), e59-e66.

HLPE. (2017). Nutrition and food systems. Rome: A report by the High Level Panel of Experts on Food Security and Nutrition of the Committee on World Food Security.

Institute for Health Metrics and Evaluation (IHME) (2019). GBD Compare Data Visualization. Seattle, WA: IHME, University of Washington, 2018. Seattle, WA: IHME, University of Washington, 2018. http://vizhub.healthdata.org/gbd-compare. Accessed 11 September 2019.

Mascagni, G., \& Mengistu, A. (2019). Effective tax rates and firm size in Ethiopia. Development Policy Review, 37(S2). https://doi.org/10. 1111/dpr. 12400
Matz, J. A., Kalkuhl, M., \& Abegaz, G. A. (2015). The short-term impact of price shocks on food security-evidence from urban and rural Ethiopia. Food Security, 7(3), 657-679.

Melesse, M. B., van den Berg, M., de Brauw, A., \& Abate, G. T. (2019). Understanding urban consumers' food choice behavior in Ethiopia: Promoting demand for healthy foods. Washington, DC: International Food Policy Research Institute (IFPRI) and Ethiopian Development Research Institute (EDRI).

Mezgabu, F., \& Tolossa, D. (2015). The Contribution of Urban Agriculture to Food Security of Individual Urban Farmers in Yeka Sub City, Addis Ababa. Ethiopian Journal of Development Research, 37(1).

Ministry of Agriculture and Natural Resources. (2017). Agricultural Extension Strategy of Ethiopia.

Nandy, S., Daoud, A., \& Gordon, D. (2016). Examining the changing profile of undernutrition in the context of food price rises and greater inequality. Social Science \& Medicine, 149, 153-163.

National Planning Commission. (2016). Growth and Transformation Plan II (GTP II) (2015/16-2019/20). http://extwprlegs1.fao.org/docs/pdf/ eth169444.pdf. Accessed 10 July 2020.

QSR International Pty Ltd. (2018) NVivo (Version 12), https://www. qsrinternational.com/nvivo-qualitative-data-analysis-software/ home. Accessed 20 Sept 2019.

Robinson, T., \& Pozzi, F. (2011). Mapping supply and demand for animal-source foods to 2030. Animal Production and Health Working Paper. No. 2. Rome.

Shapiro, B.I., Gebru, G., Desta, S., Negassa, A., Nigussie, K., Aboset, G. \& Mechal, H. (2015). Ethiopia livestock master plan. ILRI Project Report.Nairobi, Kenya: International Livestock Research Institute (ILRI).

Terfa, Z. G., Garikipati, S., Dessie, T., Lynch, S., Wigley, P., Bettridge, J. M., \& Christley, R. M. (2015). Farmers' willingness to pay for a village poultry vaccine service in Ethiopia: Prospect for enhancing rural livelihoods. Food Security, 7(4), 905-917.

The World Bank (2019). World development indicators. The World Bank.

World Food Programme. (2009). Food Security and Vulnterability in Addis Ababa, Ethiopia (p. 38pp). WFP. https://www.alnap.org/ system/files/content/resource/files/main/wfp221390.pdf. Accessed 15 July 2019.

Willett, W., Rockström, J., Loken, B., Springmann, M., Lang, T., Vermeulen, S., et al. (2019). Food in the Anthropocene: The EAT-lancet commission on healthy diets from sustainable food systems. The Lancet, 393(10170), 447-492 https.

Wolle, A., Hirvonen, K., de Brauw, A., Baye, K., \& Abate, G. T. (2020). Household food consumption patterns in Addis Ababa, Ethiopia. ESSP Working Paper 139. Washington, DC.

Yilma, Z., G.B., Emannuelle and S., Ameha. (2011). A Review of the Ethiopian Dairy Sector. Ed. Rudolf Fombad, Food and Agriculture Organization of the United Nations, Sub Regional Office for Eastern Africa (FAO/SFE), Addis Ababa, Ethiopia, pp 81.

Yu, X., \& Shimokawa, S. (2016). Nutritional impacts of rising food prices in African countries: A review. Food Security, 8(5), 985-997.

Zellelew, T. B. (2014). Meat abstinence and its positive environmental effect: Examining the fasting etiquettes of the Ethiopian Orthodox Church. Critical Research on Religion, 2(2), 134-146. https://doi. org/10.1177/2050303214535002 


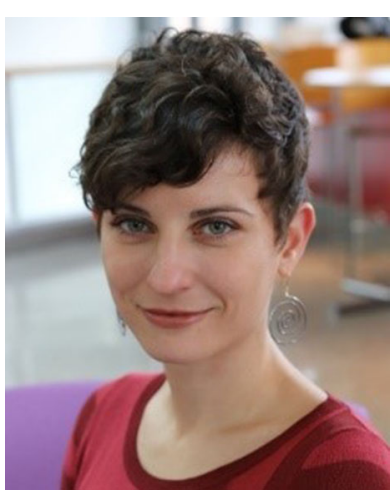

Lilia Bliznashka is a $\mathrm{PhD}$ candidate in the Department of Global Health and Population at the Harvard T.H. Chan School of Public Health. Her research interests involve the comprehensive evaluation of nutrition-sensitive agricultural programs, understanding their effectiveness and the pathways through which they work to improve maternal and child health and nutrition in low resource settings. She is also interested in the role food systems, markets and value chains play in influencing the food environment, and specifically the effectiveness and success of agricultural interventions for nutrition.

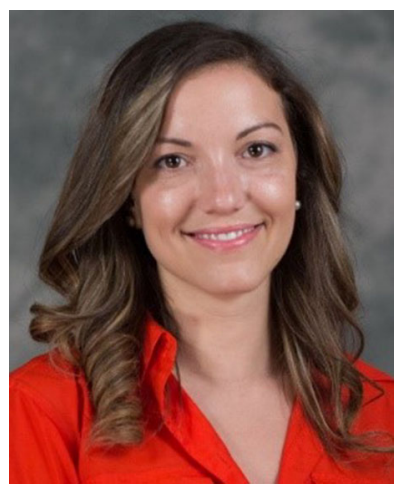

Simone Passarelli is a Postdoctoral Research Fellow in the Department of Nutrition at the Harvard T.H. Chan School of Public Health. She received a Ph.D. in Population Health Sciences from Harvard University, an M.S. in Food Policy and Applied Nutrition from Tufts University, and a B.S. in International Agriculture from Cornell University. Simone has worked at the International Food Policy Research, and consulted with PATH, Care, Action Against Hunger, and the World Food Programme. Her research focuses on agriculture, health, and nutrition linkages in low-income countries.
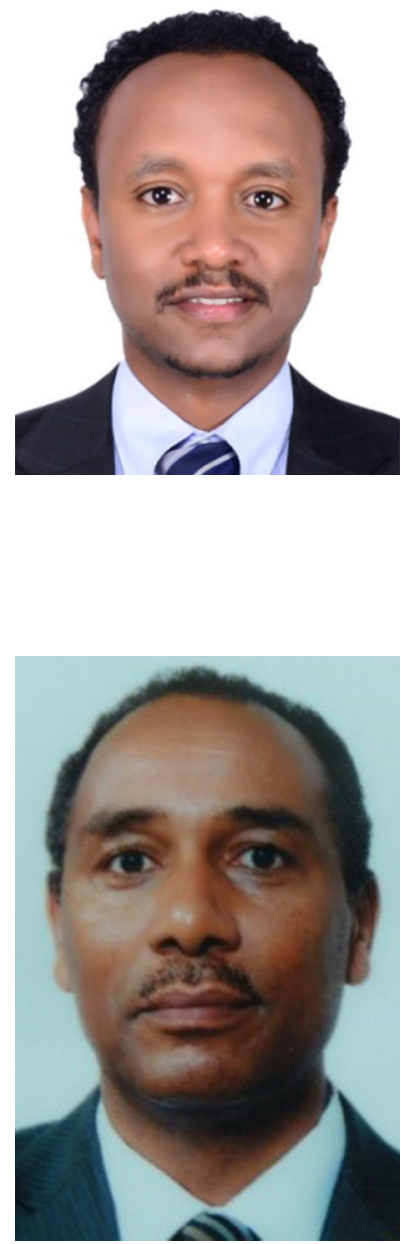

Yemane Berhane is a Professor of Epidemiology and Public Health and Director of the Addis Continental Institute of Public Health (ACIPH), situated in Addis Ababa, Ethiopia. His research has focused on maternal and child health and nutrition, HIV/AIDS, malaria, tuberculosis and other priority public health issues both in Ethiopia and globally.

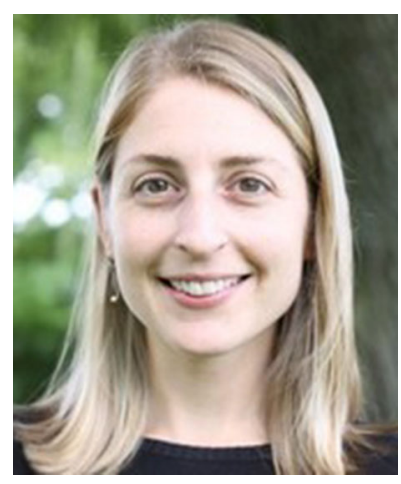

Chelsey R. Canavan, MSPH, has 10 years of experience designing and evaluating public health programs toward improving the lives of our world's most vulnerable populations. Her work focuses on the links between food systems, nutrition, and health outcomes. Chelsey's experience includes nutritional epidemiology, program evaluation, communications, and capacity building for public health programs in over a dozen countries in sub-Saharan Africa, Southeast Asia, and Central America. Chelsey was an Allan Rosenfield Global Health Fellow at the U.S. Centers for Disease Control and Prevention (CDC) and has a MSPH in Health Policy and Management from the Gillings School of Global Public Health at the University of North CarolinaChapel Hill.

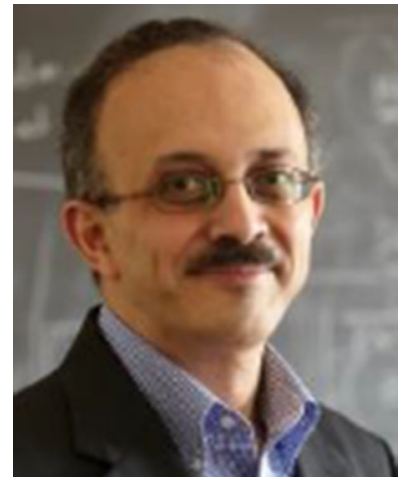

Wafaie W. Fawzi is a Richard Saltonstall Professor of Population Sciences and a Professor of Nutrition, Epidemiology, and Global Health at the Harvard T.H. Chan School of Public Health. His primary research focus is on the discovery and translation of interventions to enhance maternal and child health, nutrition and development in Africa and Asia. 